\title{
Rendgenološka analiza Blumensaatove linije $i$ položaja lateralnog interkondilarnog grebena - doprinos anatomskoj rekonstrukciji prednjeg križnog ligamenta
}

\section{Readiographic analysis of the Blumensaat's line and the location of the lateral intercondylar ridge as contribution to the anatomic anterior cruciate ligament reconstruction}

\author{
Leo Gulan ${ }^{1}$, Ana Balenović ${ }^{2}$, Hari Jurdana ${ }^{3}$, Gordan Gulan ${ }^{3 *}$
}

${ }^{1}$ Zavod za traumatologiju, Klinički bolnički centar Rijeka, Rijeka

${ }^{2}$ Medicinski fakultet Sveučilišta u Rijeci, Rijeka

${ }^{3}$ Klinika za ortopediju Lovran, Lovran

"Dopisni autor:

Prof. dr. sc. Gordan Gulan, dr. med. Klinika za ortopediju Lovran, M. Tita 1, Lovran

E-mail: gordan.gulan@gmail.com

http://hrcak.srce.hr/medicina
Sažetak. Cilj: Cilj rada bio je ispitati oblik Blumensaatove linije te utvrditi položaj lateralnog interkondilarnog grebena u odnosu na nju. Ispitanici $i$ metode: $U$ radu je korišteno 12 preparata femura sa Zavoda za anatomiju Medicinskog fakulteta u Rijeci. Na svakom preparatu tankom savitljivom žicom obilježen je lateralni interkondilarni greben. Učinjena je postranična rendgenska snimka femura uz potpuno preklapanje kondila. Na snimkama je analiziran oblik Blumensaatove linije, razlika u rendgenološkoj gustoći prikaza pojedinih dijelova te položaj lateralnog interkondilarnog grebena u odnosu na Blumensaatovu liniju. Rezultati: Na rendgenološkom prikazu Blumensaatova linija bila je ravna u $25 \%$ preparata. U $75 \%$ preparata stražnji dio linije bio je konveksan u smjeru prema distalno. S obzirom na radiografsku gustoću Blumensaatove linije mogla se podijeliti u tri dijela. Prednji i stražnji dio imali su gustoću intenziteta kortikalne kosti, dok je gustoća srednjeg dijela odgovarala intenzitetu spongiozne kosti. Lateralni interkondilarni greben spaja se s Blumensaatovom linijom u točki koja stražnji segment dijeli u omjeru $58 \%$ : $42 \%$. Lateralni greben s Blumensaatovom linijom zatvara kut od $62.4^{\circ}$. Zaključak: Blumensaatova linija u $75 \%$ analiziranih preparata nije ravna, već je u stražnjem dijelu zaobljena s konveksitetom usmjerenim prema distalno. Na profilnoj RTG snimci LIR koljena zatvara kut od 62,40.

Ključne riječi: anatomija; interkondilarna udubina; prednji križni ligament; rendgen

Abstract. Aim: The aim of this study was to analyze the shape of the Blumensaat's line and the relationship with lateral intercondylar ridge on the lateral radiographic view. Patients and Methods: On twelve femoral specimens, the lateral intercondylar ridge were labeled with the thin wire. A full lateral view with the distal femur was taken. At the X-ray we analyzed the radiographic shape of the Blumensaat's line and a possible difference of the radiographic density during its course. The angle between lateral intercondylar ridge and Blumensaat's line was calculated as well. Results: The Blumensaat's line was straight in $25 \%$ of specimens. In $75 \%$ the posterior part had convexity. Regarding the radiographic density the BL could be divided into three parts. The density of the anterior and posterior was similar as the cortical bone, while the middle part corresponds to the cancellous bone. The posterior part was the longest. The lateral intercondylar ridge and the Blumensaat's line formed the angle of average 62,40 and intersect with the LIR at the point which divides the posterior part of the BL at the $58 \%: 42 \%$ ratio. Conclusion: In $25 \%$ the Blumensaat's line was straight. In $75 \%$ of the specimens the posterior convexity was observed. The lateral interc ondylar ridge and the Blumenssat's line formed the angle of the 62,50 . They intersected at the point which divides the posterior part in the 58:42 ratio.

Key words: anterior cruciate ligament; Blumensaat line; interocondylar nostch; plain radiography 


\section{UVOD}

Ozljeda prednjeg križnog ligamenta jedna je od najčešćih ozljeda koljena. Puknuće ligamenta može uzrokovati nestabilnost koljena ne samo pri sportskim aktivnostima, već ponekad i pri obavljanju svakodnevnih aktivnosti. Kao posljedica ovih ozljeda jest i razvoj prijevremenog osteoartritisa koljena ${ }^{1,2}$.

Tijekom povijesti više tehnika je korišteno za rekonstrukciju prednjeg križnog ligamenta. Uvedena je tehnika postavljanja ligamenta u izometrične točke, pri čemu se duljina vlakana najmanje mijenja $^{3}$. Nakon toga uvedena je tehnika orijentacije po „kazaljkama na satu“ u kojoj se femoralni tunel postavlja u položaj kazaljke od 1 sat za desno i 11 sati za lijevo koljeno ${ }^{4}$. Niti jedna od ovih tehnika nije se pokazala dovoljno dobra u dugoročnom praćenju pacijenata. Danas zlatni standard predstavlja anatomska tehnika rekonstrukcije prednjeg križnog ligamenta i individualizirani pristup ${ }^{5,6}$.

Prema ovoj tehnici potrebno je anatomski rekonstruirati polazišta ligamenta na tibiji i femuru, te njihovu duljinu i napetost ${ }^{5}$.

Za planiranje i izvođenje anatomske rekonstrukcije potrebno je postavljanje tunela u područje anatomskog hvatišta prednjeg križnog ligamenta na femuru i tibiji, bez obzira radi li se o tehnici rekonstrukcije $s$ jednim snopom ili se rekonstruiraju posebno anteromedijalni i posterolateralni snop. Poznato je da su tehničke pogreške pri zahvatu, a naročito pri postavljanju femoralnog tunela, glavnim uzrokom funkcionalno insuficijentnog presatka ili njegove rupture ${ }^{7,8}$. Zbog ovih rezultata u posljednje vrijeme velika se pažnja posvećuje pronalaženu optimalne tehnike za anatomsku rekonstrukciju femoralnog hvatišta ACL-a ${ }^{9}$. Kako bi se tuneli postavili u željenu poziciju koriste se različite anatomske orijentacijske točke, kako za planiranje i poslijeoperacijsku analizu, tako i tijekom samog zahvata. Intraoperacijski najkorišteniji anatomski orijentir je greben koji se nalazi na medijalnoj strani lateralnog kondila femura, poznat pod nazivom lateralni interkondilarni greben (LIR od engl. lateral intercondylar ridge) koji omeđuje femoralno hvatište s gornje i prednje stra$n e^{10}$.

Najčešća radiografska metoda pri određivanju centra femoralnog tunela je metoda po Bernardu i Hertelu ${ }^{11}$. U ovoj metodi osnova za postavljanje mreže kvadrata je Blumensaatova linija (BL). Tu liniju Blumensaat je opisao 1938. godine kao ravnu liniju na rendgenskoj profilnoj snimci koljena koja odgovara krovu interkondilarne udubine ${ }^{12}$. U radu su postavljene dvije hipoteze: 1 ) da je BL radiografski nejednake gustoće, te varijabilnog oblika; 2) da je moguće odrediti položaj LIR-a na postraničnoj radiografskoj snimci koljena.

$\mathrm{Na}$ analiziranim RTG snimkama Blumensaatova linije bila je ravna u $25 \%$ ispitivanih femura, a u $75 \%$ uzoraka stražnji dio bio je zaobljen s konveksitetom usmjerenim prema distalno.

\section{ISPITANICI I METODE}

Analizirano je 12 preparata femura sa Zavoda za anatomiju medicinskog fakulteta u Rijeci. Spol i dob nisu bili poznati. Prije korištenja femura provjerili smo ako se na medijalnom zidu lateralnog kondila nalazi dobro vidljiv LIR (slika 1). Duž grebena, po njegovu vrhu, transparentnom trakom fiksirali smo tanku, savitljivu žicu. Femur smo bočno fiksirali u držaču tako da smo poravnali kondile u distalnom i stražnjem dijelu kako bismo

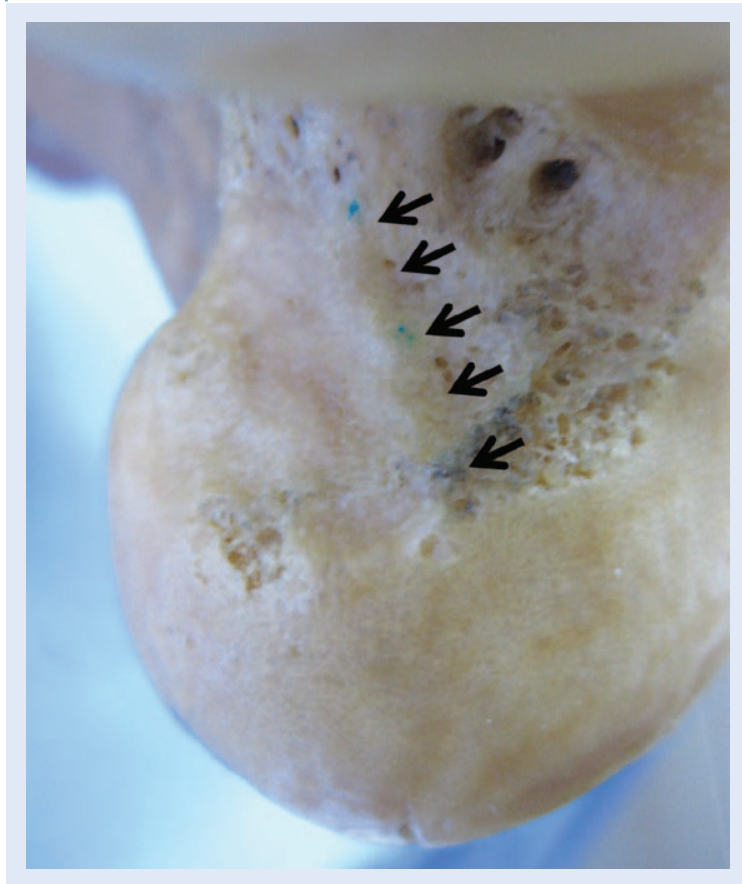

Slika 1. Anatomski preparat distalnog femura. Strjelice označavaju lateralni interkondilarni greben 


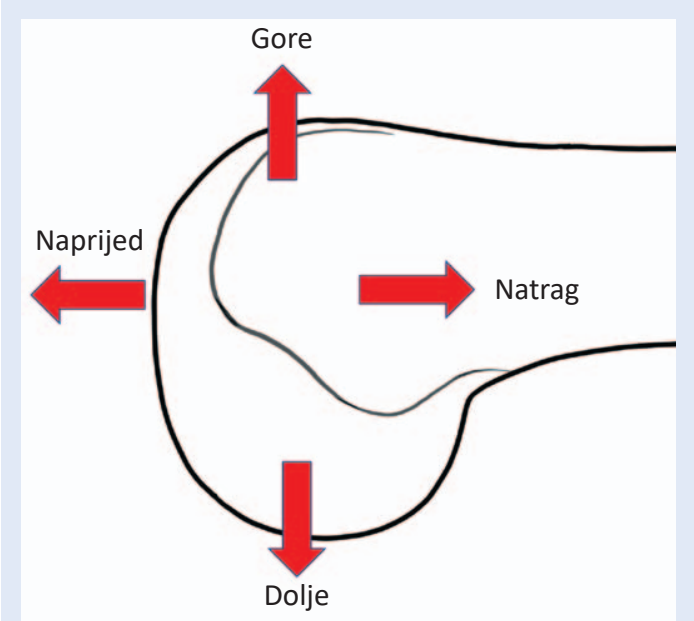

Slika 2. Orijentacijski smjerovi pri opisu rendgenskih slika

dobili pravu postraničnu snimku femura ${ }^{13}$. U navedenom položaju učinjen je klasični rendgenski snimak. Rendgenske snimke dobivene na klasičnim filmovima skenirane su skenerom za transparentne medije kako bi se spriječile moguće distorzije snimki pri njihovu pretvaranju u digitalni oblik. Način orijentacije tijekom opisivanja rezultata prikazan je na slici 2 (slika 2). Na tako dobivenim RTG snimkama analizirali smo Blumensaatovu liniju, odnosno krov interkondilarne udubine. Najprije smo nacrtali idealni BL (iBL) koju smo dobili spajanjem prednjeg i stražnjeg ruba krova interkondilarne udubine. Odmicanje pojedinih dijelova BL-a, dobivene na ispitivanim preparatima, od iBL-a prema proksimalno označili smo kao minus varijantu (-BL), odmicanja prema distalno kao plus varijantu (+BL). Poklapanje $\mathrm{s}$ iBL-om označili smo kao nula (OBL) varijantu.

Vizualno je analizirana rendgenološka gustoća $B L-a$. Kao referentne vrijednosti odredili smo 2 intenziteta gustoće, a to su: intenzitet kortikalne kosti i intenzitet spongiozne kosti. Nakon analize BL-a analizirali smo položaj LIR-a u odnosu na BL, mjereći kut koji ove dvije linije zatvaraju i određivanjem točke u kojoj se LIR spaja s BL-om. Za sva mjerenja korišten je ImageJ program.

\section{Statistika}

Za statističku obradu podataka korišten je program Excell (MS office 365). Rezultati su prikazani relativnim vrijednostima (postocima), te su izračunati medijani i rasponi.

\section{REZULTATI}

U svih 12 analiziranih femura, na RTG prikazu krova interkondilarne udubine (BL) mogla su se uočiti 3 dijela različite rendgenske gustoće. Granica između segmenata određivana je subjektivno, a određivali su je 2 liječnika zasebno. Rendegnološka gustoća BL-a u prednjem dijelu (A) i stražnjem dijelu (C) odgovarala je gustoći prikaza kortikalne kosti, dok gustoća srednjeg dijela (B) odgovara više gustoći spongiozne kosti. Analiza duljine pojedinih segmenata pokazala je da je C segment najdulji. Medijan njegove duljine iznosio je $60 \%$ (s rasponom 11,87\%) duljine iBL-a. U tri analizirana preparata ( $25 \%$ ) položaj stražnjeg segmenta poklapao se s iBL-om i označeni su kao OBL tip. U 9 (75 \%) ispitivanih uzoraka stražnji dio bio je iz-

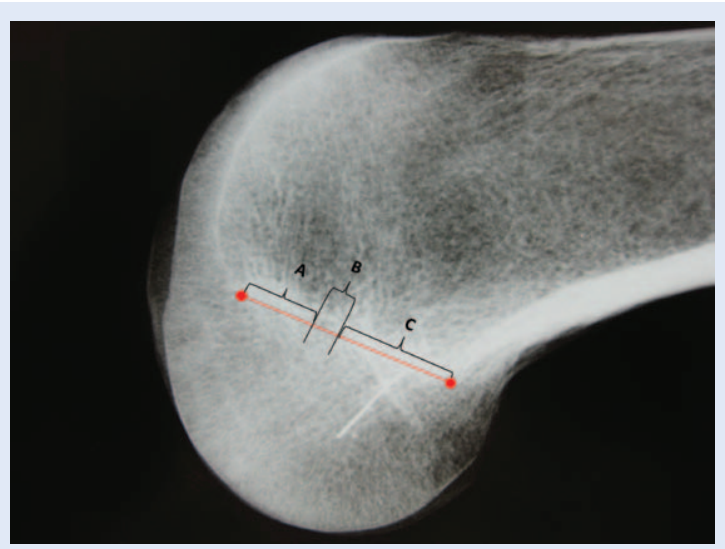

Slika 3. Podjela Blumensaatove linije (BL) s obzirom na gustoću RTG sjene. A i C segmenti s većom RTG gustoćom; B - segment s manjom RTG gustoćom

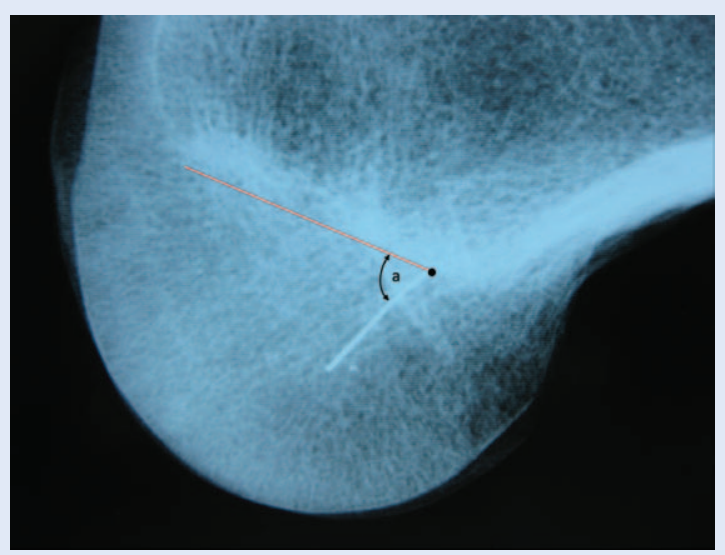

Slika 4. Mjerenje kuta (a) koji zatvaraju BL i LIR; BL - Blumensaatova linija (crveno) dobije se spajanjem točke na proksimalnom kraju lateralnog interkondilarnog grebena (LIR) i prednjeg ruba interkondilarne udubine 
bočen prema distalno u donosu na iBL u obliku trbuha i odgovarao je +BL tipu. Medijan duljine prednjeg segmenta iznosio je $21,11 \%$ (raspon $16,44 \%)$, a medijan duljine najkraćeg, srednjeg segmenta iznosio je 18,89\% (raspon 4,92 \%) duljine iBL-a (slika 3). Nakon toga mjeren je kut koji su zatvarali BL i linija koja je predstavljala LIR. Medijan kuta iznosio je $62,42^{\circ}$ (raspon $3,52^{\circ}$ ) (slika 4).

Sljedećom analizom određivali smo položaj točke u kojoj se LIR spaja s C segmentom BL-a. Na preparatima ravnog interkondilarnog krova, gdje se LIR direktno spajao s iBL-om, izmjerili smo duljinu C segment ispred (C1) i iza točke (C2), spajanja (x), te izračunali njihovu duljinu u odnosu na duljinu $C$ segmenta (slika 5). U +BL tipu, položaj točke spajanja LIR-a i BL-a dobili smo tako da smo iz točke x povukli okomicu na iBL. Dio C segmenta ispred točke spajanja označen je s C1, a iza s C2. Nakon toga

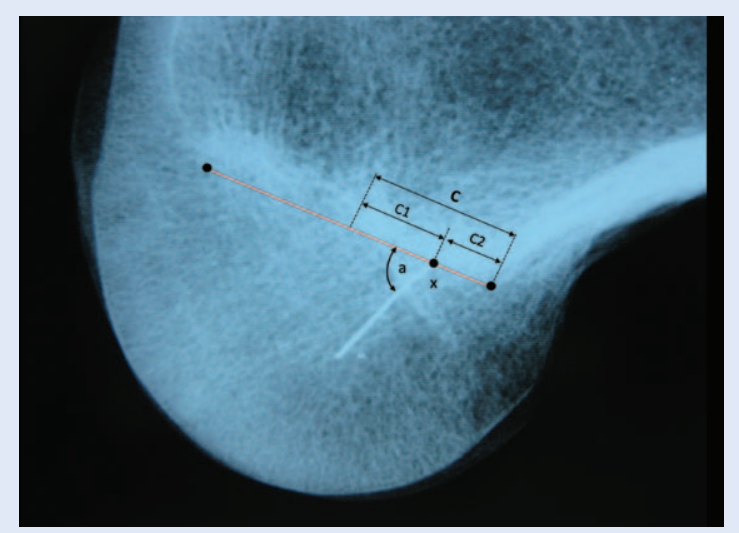

Slika 5. Određivanje točke spajanja BL-a i LIR-a (x) na RTG snimkama preparata s ravnom Blumensaatovom linijom

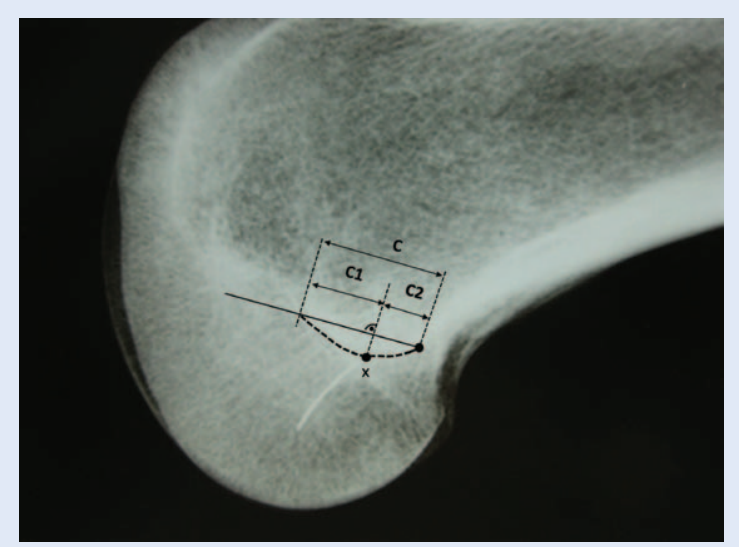

Slika 6. Određivanje točke spajanja LIR-a i BL-a (x) na preparatima s konveksnim stražnjim dijelom Blumensaatove linije smo, kao i ranije, odredili postotni duljinu C1 i C2 u odnosu na $\mathrm{C}$ segment BL-a (slika 6).

Rezultati su pokazali da u obje varijante BL-a (OBL tipu i +BL tipu) C1 vrijednost medijana iznosi $57,61 \%$ (raspon 4,76\%), što bi značilo da se LIR spaja s BL-om u točki koja C segment dijeli približno na omjer $60: 40$.

\section{RASPRAVA}

Dosadašnji radovi pokazali da oko $50 \%$ revizija ACL-a nastaje zbog tehničke pogreške prilikom izvođenja zahvata. Gafalo i sur. u svojoj seriji revizija rekonstrukcije ACL-a pronašli su da je u $79 \%$ ispitanika revizija učinjena zbog loše pozicioniranog femoralnog tunela. Multicentrična studija MARS grupe (od engl. Multicenter ACL Revision Study) također je pokazala da je $80 \%$ revizija učinjeno zbog iste pogreške ${ }^{14}$. Odensten je dokazao da postavljanje femoralnog tunela izvan anatomskog hvatišta značajno utječe na njegovo istezanje u fleksiji i ekstenziji ${ }^{15}$. Markolf i suradnici pokazali su da pomicanje tunela za $5 \mathrm{~mm}$ izvan anatomskog hvatišta povećava sile istezanja za $62 \%{ }^{16}$. Herbort i sur. dokazali su da čak i manja odstupanja od gore navedenih značajno mijenjaju kinematiku koljena ${ }^{17}$. Iz gore navedene literature vidljivo je da su češće pogreške pri postavljanju femoralnog tunela u usporedbi s tibijalnim tunelom, pa je taj dio zahvata proglašen najslabijom karikom u lancu rekonstrukcije $A C L-a^{14,18,19}$. Zbog navedenog je velik znanstveni i stručni interes posvećen određivanju anatomije femoralnog hvatišta i pronalaženju anatomskih operacijskih tehnika za njegovu rekonstrukciju Do sada je predloženo više rendgenoloških metoda koje pomažu pri određivanju centra femoralnog hvatišta ACL-a $a^{11,20-22}$. Najraširenija je i najupotrebljavanija metoda koju su 1997. godina razvili Bernard i Hertel. Na RTG snimci konstruirali su sustav kvadrata prislonjen uz $\mathrm{BL}^{11}$. Kvadrat je uzdužnim i poprečnim crtama podijeljen na četvrtine. Centar ligamenta određuje se s obzirom na položaj unutar mreže kvadrata. Autori su opisali ovu RTG metodu uz pretpostavku da je BL ravna linija. Yahagi i sur. su, analizirajući krov interkondilarne udubine na sagitalnom presijeku anatomskih preparata, zaključili da je u $65 \%$ uzoraka u stražnjem dijelu krov interkondilarne udu- 
bine izbočen prema distalno, dok je u $35 \%$ uzoraka bio ravan, što bi moglo značajno utjecati na primjenjivost Bernardove metode ${ }^{23}$. Naši rezultati dobiveni analizom RTG slika također pokazuju da u većini slučajeva BL nije ravna crta, ali se ne podudaraju u cijelosti s rezultatima dobivenim analizom kadaveričnih preparata prije spomenutih autora. Razlog ovog odstupanja mogao bi ležati u načinu prikaza krova interkondilarne udubine. Na RTG snimkama BL nastaje kao zbroj svih sagitalnih presjeka kroz krov interkondilarne

Veličina kuta koji zatvaraju Blumensaatova linija i lateralni interkondilarni greben iznosi $62,4^{\circ} \pm 1,9^{\circ}$. Lateralni interkondilarni greben spaja se $s$ Blumensaatovom linijom u točki koja stražnji segment dijeli u omjeru približno $60: 40$.

udubine čitavom njegovom širinom. Na kadaveričnim preparatima oblik krova analizira se samo na jednom presjeku, koji je učinjen kroz najvišu točku ulaza u interkondilarnu udubinu. Kako bi se izbjegle moguće zabune i nesporazumi pri opisivanju oblika krova interkondilarne udubine na RTG-u i anatomskim preparatima, predlažemo korištenje naziva BL za RTG snimke, a naziv „vrh krova interkondilarne udubine“ za anatomske preparate. Prema većini autora najvažniji intraoperacijski orijentir za postavljanje femoralnog tunela je LIR $^{23}$. lako je položaj grebena proučavalo više studija, prema nama dostupnim podatcima postoji samo jedna studija koja je analizirala položaj grebena na RTG snimkama ${ }^{24}$. Farrow i sur. izračunali su da LIR i BL tvore kut od 75,5 ${ }^{\circ}$. U našem radu kut koji tvoje BL i LIR iznosi $62,42^{\circ}$ ( \pm $\left.1,9^{\circ}\right)$. Razlike u dobivenim prosječnim vrijednostima mogu se tumačiti oblikom BL-a u analiziranim uzorcima. Dok su Farrow i sur. analizirali isključivo BL koja je ravni i u cijelosti se poklapa s iBL-om, mi smo u $75 \%$ uzoraka pri mjerenju kuta LIR-BL analizirali +BL varijantu, za koju je i dokazano da je učestalija u općoj populaciji ${ }^{25}$. Kako bismo prijeoperacijski mogli odrediti položaj LIR-a na RTG snimkama u procesu planiranja ili analize operacija, osim kuta LIR-BL moramo odrediti točku u kojoj se ove linije spajaju. Farrow i sur. sjecište BL-LIR dobili su tako što su duljinu BL multiplicira- li s faktorom 0,79 , što predstavlja prosječnu vrijednost omjera duljine BL-a i LIR-a. Dobivena vrijednost izražena je u milimetrima i predstavlja sjecište BL-a i LIR-a mjereno od stražnjeg posterolateralnog ruba interkondilarne udubine. Naša metoda primjenjiva je za sve oblike i različite dužine BL-a i prema njoj sjecište BL-LIR nalazi se $u$ točki koja C segment dijeli približno na omjer 60 : 40. Kako su C1 i C2 relativne duljine, mjerenje je primjenjivo bez obzira na veličinu koljena ili RTG povećanje. Ograničenja studije su: 1. Analizirani broj femura relativno je mali. Trebalo bi analizirati veći broj uzoraka kako bi se vidjelo mogu li dobiveni rezultati biti primjenjivi pri kliničkom radu; 2. lako dobro uočljive promjene gustoće na RTG snimkama, analizirane su vizualno i subjektivno kao i granice između pojedinih segmenata BL-a. Zaključak: Na temelju rendgenološke gustoće, Blumensaatova linija može se podijeliti u tri segmenta. Stražnji segment je u 75 \% slučajeva izbočen prema distalno. Kut koji zatvaraju LIR i BL iznosi $62,4^{0} \pm 1,9^{\circ}$, a točka u kojoj LIR i BL stražnji segment dijeli u omjeru približno $60: 40$.

Klinička važnost: varijanta +BL-a mogla bi značajno utjecati na primjenu Bernadove metode kvadranata. Brzo i jednostavno RTG određivanje položaja LIR-a moglo bi olakšati pripremu i poslijeoperacijsku analizu pri određivanju položaja femoralnog tunela.

Izjava o sukobu interesa: Autori izjavljuju da ne postoji sukob interesa.

\section{LITERATURA}

1. Li RT, Lorenz S, Xu Y, Harner CD, Fu FH, Irrgang JJ. Predictors of radiographic knee osteoarthritis after anterior cruciate ligament reconstruction. Am J Sports Med 2011;39:2595-603.

2. Øiestad BE, Holm I, Aune AK, Gunderson R, Myklebust $G$, Engebretsen $L$ et al. Knee function and prevalence of knee osteoarthritis after anterior cruciate ligament reconstruction: A prospective study with 10 to 15 years of follow-up. Am J Sports Med 2010;38:2201-10.

3. Artmann M WC. Investigation of the appropriate functional replacement of the anterior cruciate ligament. Z Orthop Ihre Grenzgeb 1974;112:160-5.

4. Bylski-Austrow DI, Grood ES, Hefzy MS, Holden JP, Butler DL. Anterior cruciate ligament replacements: A mechanical study of femoral attachment location, flexion angle at tensioning, and initial tension. J Orthop Res 1990;8: 522-31.

5. Hofbauer M, Muller B, Murawski CD, van Eck CF, Fu FH. The concept of individualized anatomic anterior cruciate 
ligament $(\mathrm{ACL})$ reconstruction. Knee Surgery, Sports Traumatology, Arthroscopy 2014;22:979-86.

6. Araujo PH, Kfuri Junior M, Ohashi B, Hoshino Y, Zaffagnini S, Samuelsson K et al. Individualized ACL reconstruction. Knee Surgery, Sport Traumatol Arthrosc 2014;22: 1966-75.

7. Allen $\mathrm{CR}$, Giffin JR HC. Revision anterior cruciate ligament reconstruction. Clin North Am 2003;34:79-98.

8. Trojani C, Sbihi A, Djian P, Potel JF, Hulet C, Jouve F et al. Causes for failure of $A C L$ reconstruction and influence of meniscectomies after revision. Knee Surgery, Sport Traumatol Arthrosc 2011;19:196-201.

9. Piefer JW, Pflugner TR, Hwang MD, Lubowitz JH. Anterior Cruciate Ligament Femoral Footprint Anatomy: Systematic Review of the 21st Century Literature. Arthrosc J Arthrosc Relat Surg 2012;28:872-81.

10. Hutchinson MR, Ash SA. Resident's ridge: assessing the cortical thickness of the lateral wall and roof of the intercondylar notch. Arthroscopy 2003;19:931-5.

11. Bernard $M$, Hertel $P$, Hornung $H$, Cierpinski T. Femoral insertion of the ACL. Radiographic quadrant method. Am J Knee Surg 1997;10:14-21.

12. Blumensaat C. Die Lageabweichungen und Verrenkungen der Kniescheibe. In: Ergebnisse der Chirurgie und Orthopädie 1938;31:149-223.

13. Farrow LD, Gillespie RJ, Victoroff BN, Cooperman DR. Radiographic location of the lateral intercondylar ridge: its relationship to Blumensaat's line. Am J Sports Med 2008;36:2002-6.

14. Wright RW, Huston LJ, Spindler KP, Dunn WR, Haas AK, Allen CR et al. Descriptive epidemiology of the multicenter ACL revision study (MARS) cohort. Am J Sports Med 2010;67:257-62.

15. Odensten $\mathrm{M}$, Gillquist J. Functional anatomy of the anterior cruciate ligament and a rationale for reconstruction. J Bone Jt Surg - Ser A 1985;67:257-62.

16. Markolf KL, Hame S, Hunter DM, Oakes DA, Zoric B, Gause $P$ et al. Effects of femoral tunnel placement on knee laxity and forces in an anterior cruciate ligament graft. Journal of Orthopaedic Research 2002;20:1016-24.

17. Herbort M, Domnick C, Raschke MJ, Lenschow S, Förster $\mathrm{T}$, Petersen $\mathrm{W}$ et al. Comparison of Knee Kinematics after Single-Bundle Anterior Cruciate Ligament Reconstruction via the Medial Portal Technique with a Central Femoral Tunnel and an Eccentric Femoral Tunnel and after Anatomic Double-Bundle Reconstruction. Am J Sports Med 2016;44:126-32.

18. Ahn JH, Jeong HJ, Ko CS, Ko TS, Kim JH. Three-dimensional reconstruction computed tomography evaluation of tunnel location during single-bundle anterior cruciate ligament reconstruction: A comparison of transtibial and 2-incision tibial tunnel-independent techniques. Clin Orthop Surg 2013;5:26-35.

19. Morgan JA, Dahm D, Levy B, Stuart MJ, MARS Study Group. Femoral tunnel malposition in ACL revision reconstruction. J Knee Surg 2012;25:361-8.

20. Mochizuki T, Muneta T, Nagase T, Shirasawa S ichi, Akita K ich, Sekiya I. Cadaveric Knee Observation Study for Describing Anatomic Femoral Tunnel Placement for TwoBundle Anterior Cruciate Ligament Reconstruction. Arthrosc - J Arthrosc Relat Surg 2006;22:356-61.

21. Watanabe $S$, Satoh $T$, Sobue $T$, Koga $Y$, Oomori G NA. Three dimensional evaluation of femoral tunnel position in anterior cruciate ligament reconstruction. Hiza J Japan Knee Soc 2005;30:253-6.

22. Takahashi M, Doi M, Abe M, Suzuki D, Nagano A. Anatomical Study of the Femoral and Tibial Insertions of the Anteromedial and Posterolateral Bundles of Human Anterior Cruciate Ligament. Am J Sports Med 2006;34:78792.

23. Ferretti M, Ekdahl M, Shen W, Fu FH. Osseous landmarks of the femoral attachment of the anterior cruciate ligament: an anatomic study. Arthroscopy 2007;23:1218-25.

24. Iriuchishima T, Ryu K, Aizawa S, Fu FH. Blumensaat's line is not always straight: morphological variations of the lateral wall of the femoral intercondylar notch. Knee Surgery, Sport Traumatol Arthrosc 2016;24:2752-7. 